Revista de Sociología 30(2020):105-117

DOI: https://doi.org/10.15381/rsoc.v0i30.18908

ISSN impreso: 1605-8933 / ISSN en línea: 1609-7580

\title{
Geopolítica internacional y pandemia
}

Sección ESTUDIOS

RECIBIDO: $31 / 07 / 2020$

APROBADO: 30/08/2020

PUBLICADO ONLINE: 23/10/2020
Eduardo Arroyo Laguna

Universidad Ricardo Palma, Lima

eduardoarroy029@gmail.com

https://orcid.org/0000-0002-8316-9164

\section{RESUMEN}

El modelo global neoliberal ha sido paralizado por esta pandemia. Sin embargo, no ha aminorado la lucha entre las potencias, Estados Unidos de Norteamérica y China Popular, por el control mundial. PALABRAS CLAVE: geopolítica internacional; modelo neoliberal global; pandemia.

\section{International geopolitics and pandemic}

\section{ABSTRACT}

The global neoliberal model has been paralyzed by this pandemic. However, it has not lessened the struggle between the powers, the United States of America and People's China, for world control. KEYWORDS: International geopolitics; global neoliberal model; pandemic. 


\section{Introducción}

$\mathrm{L}$

a geopolítica internacional, entendida como la ciencia que estudia la distribución del poder del planeta de parte de las potencias mundiales, nos revela que tanto Estados Unidos de Norteamérica como la República Popular China han renovado su lucha a pesar del hecho inédito de una pandemia que viene asolando a todos los continentes.

El Estado se ha hecho presente en bien de las mayorías poblacionales ante una economía de mercado que no suele considerar las necesidades públicas. Hacia el futuro se ha de resolver la contraposición entre un modelo global neoliberal que privilegia al mercado invisibilizando al Estado y la reaparición del Estado atendiendo la cosa pública.

En estos tiempos, la humanidad vive acosada por un virus invasor. Sabemos que toda especie viva tiene sus virus y bacilos. Se trasladan con ellos e infectan a otras especies no inmunizadas. Podemos decir que la pandemia del coronavirus es hija de la gran crisis ecológica actual, generada por la actitud ecodepredadora de las corporaciones transnacionales que invaden territorios ajenos llevando a las especies vivas a retirarse de sus suelos ancestrales, en un acto de dominación. Rompen, así, la comunión con la naturaleza, quebrando ambientes forjados en años de vinculación.

Es, además, la crisis de un marco civilizatorio, una concepción que entiende que dominar la naturaleza es desintegrarla y echar por tierra los equilibrios que ella misma ha logrado. Se siembra el caos ignorando que los seres humanos somos elementos esenciales de la evolución de las cosas y que es en la historia como se organiza la vida de la humanidad. En suma, somos productos naturales que al trabajar nos transformamos y nos forjamos en el decurso de los siglos. Podemos, conforme aseguramos nuestra supervivencia, planificar nuestra realización a largo plazo vertebrando una estructura de poder con los otros seres humanos y el resto de especies vivas (Quijano, 2010). Mantendremos, de este modo, el manejo del trabajo, el sexo, las subjetividades, autoridades y relaciones con otras especies y el resto del universo.

Para el caso latinoamericano, la invasión europea impuso la racialización como eje del sistema de dominación. Unas razas fueron consideradas superiores y otras inferiores separándolas de sus ambientes naturales. Los pueblos amerindios, siempre muy ligados a la tierra y al dios sol, vieron afectados su cultura y normas de vida. Colonizados sus territorios, perdieron su soberanía y se intentó negar sus aportes civilizatorios: lengua, religión, lazos de sangre, pautas de trabajo, vida en 
comunidad y diversos diseños culturales propios de la vida en colectividad. Se estableció una visión eurocéntrica de la existencia tirándose por la borda todo aporte de los pueblos originarios de América, a los que se vilipendió y calificó de bárbaros e ignorantes.

Con el paso del tiempo, se ha impuesto el capitalismo norteamericano, denominado "capitalismo salvaje", el que pivota en torno al mercado excluyendo al Estado. La actual globalización neoliberal de égida estadounidense ha implicado la sinonimia entre occidentalización y globalización. El antiguo modelo europeo de construcción capitalista que había establecido una relación armónica entre la economía, la sociedad y el Estado logró resultados favorables para su población por un tiempo, hasta que la globalización neoliberal invadió sus fueros. El sistema asiático de construcción capitalista implica que desde el Estado se regula a la economía de mercado.

Pese a que la globalización ha buscado borrar las fronteras y estandarizar un estilo de vida, asunto en el que ha avanzado en gran medida al lograr que el espacio y el tiempo se hagan universales para todos, no ha podido evitar que florezcan multitud de culturas vernaculares, lo que lleva a advertir que hay un nacionalismo ad-portas y que este no ha muerto: "porque la pérdida de la certeza del progreso, la pérdida de un futuro prometido provoca el retorno al pasado [...] de ahí una reelaboración de las raíces étnicas, religiosas, etc. El Estado-nación no debe ser abolido [...]. No disolución sino integración en busca de nuestra identidad terrestre, consciencia de la comunidad en el seno de la humanidad dentro de una era planetaria" (Morin Edgar, 2007, p. 2).

\section{Las diversas plagas que han asolado a la humanidad}

La humanidad recuerda, a lo largo de los tiempos, aniquilaciones que van desde el estallido de volcanes y poblaciones arrasadas por ríos de lava así como terremotos y tsunamis que han arrasado islas sepultándolas; pero en realidad son las pandemias las que más han desaparecido poblaciones.

Los grandes asesinos de la historia son las bacterias y los virus. Desde la famosa Peste de Justiniano, emperador bizantino, que vio arrasada a Constantinopla, la sede central del imperio romano de oriente hasta la peste bubónica o negra que en el siglo XIV (1346 a 1353) mató a un 60\% de pobladores europeos. La viruela se llevó a un $30 \%$ de mortales en Europa.

A inicios del siglo XX, entre 1914 a 1919, en plena Primera Guerra Mundial se registra en un hospital norteamericano la que luego se conocería como la gripe 
española, ya que España, país neutral en esta guerra, fue quien tuvo la mayor cantidad de fallecidos. Años después, en 1957, desde Asia, península china de Yunán, se propagó la gripe asiática que causó un millón de muertos. Otra plaga asiática, la gripe de Hong Kong, ocasionó otro millón de fallecidos.

EI VIH-SIDA, ha asolado al planeta desde 1981 agotando el sistema inmunológico de las personas, muchas de las que fallecen por quedar inermes al contagio de otras enfermedades. Más recientes, son una serie de epidemias, todas procedentes de Asia, todas ellas de alta letalidad. El COVID-19 es con toda seguridad la epidemia mayor.

Pudieron ser mejor manejadas si se hubiera hecho caso a las advertencias del mundo académico, pero los presidentes y ejecutivos no hicieron caso de estos informes.

\section{Ante la incertidumbre vuelve el estado protector}

Esta epidemia internacional ha detenido al modelo global y ha confinado en sus domicilios a gran parte de la humanidad. El sistema ha pasado de ser ampliamente extravertido, social, a la primacía de la introversión. De hecho, la globalización ha fabricado muchas vidas vacías y sin sentido, incapaces de estar a solas. Pienso que en el futuro se desarrollarán una serie de depresiones, suicidios, neurosis, acentuación de las misoginias y misantropías; así como enfermedades mentales propias de esta etapa de confinamiento y miedos globales (xenofobia, homofobia, racismo, supremacismo blanco).

Se derrumban todas las certezas de la vida de las que vivía olímpicamente el modelo global neoliberal predicando un lenguaje único, una extraña dictadura omnipotente del mercado que dejaba de lado al Estado (Forrester Viviane, 2002, p. 13).

La gente no clama al mercado para resolver los actuales problemas de desempleo, hambre y muertes masivas, sino invoca al Estado porque sabe que el mercado no ha resuelto ni resolverá nada. Vuelve el Estado protector en defensa de todos. Es de suponer que de un lado prime el instinto de conservación, de supervivencia, que acentuará el individualismo pero, al mismo tiempo, se ven casos de solidaridad, lo que debe llevar a fuertes campañas de fraternidad en la hora actual. "Esta crisis es el enésimo ejemplo del fracaso del mercado. Y un ejemplo también de la realidad de la amenaza de una catástrofe medioambiental. El asalto neoliberal ha dejado a los hospitales desprovistos de recursos. Las camas de los hospitales fueron suprimidas en nombre de la 'eficiencia económica'... El Gobierno estadounidense y las multinacionales farmacéuticas sabían, desde hace años, que existía una gran 
probabilidad de que se produjese una pandemia. Pero, como prepararse para ello no era bueno para los negocios, no se hizo nada" (Chomsky Noam, 2020).

Los cambios drásticos de la hora presente permiten el retorno de la presencia del Estado y de una serie de reivindicaciones populares, lo que no recibe ninguna objeción ni crítica del modelo global imperante. Las viejas acusaciones de ser medidas comunistas, socialistas, populistas pierden piso y son dejadas de lado.

Los pobres son los sectores más golpeados y muchas clases medias han retornado a su núcleo inicial de pobreza. La gran inversión está siendo canalizada en bien de la gente necesitada y menesterosa. ¿Para qué se ha ahorrado en todos estos años si no es para estos tiempos duros, de crisis global?

Incluso, la propia gravedad de la pandemia impulsa esfuerzos continentales, lo que podría acentuar la integración regional, no bajo la égida estadounidense sino una integración soberana sobre la base de recuperar la región para sus connacionales, una integración para firmar acuerdos continentales de lograr la vacuna para nuestros países evitando la rivalidad fratricida, el cuidado soberano de nuestros recursos: agua, petróleo, gas, pesca, agro, ganado, bosques. El triunfo sobre esta epidemia requerirá de alianzas regionales y globales, en lo que nuestra región puede aprovechar a favor el gran potencial de sus riquezas naturales, su megadiversidad y el trabajo de su población y modos conductuales de cuidar la naturaleza.

Puede darse el caso de que la sociedad ponga el peso de la balanza en sus gobiernos nacionales más que en el mercado global. La novedad es que ha vuelto el viejo Estado, denostado e injuriado como ineficiente, a presentar sus servicios a todos por igual. Los más desfavorecidos se aferran a él como única y última esperanza. Los intelectuales preveen un vuelco en estos tiempos.

Así la percibe quien sostiene que "COVID-19 está obligando a los gobiernos, empresas y sociedades a fortalecer su capacidad para hacer frente a largos períodos de autoaislamiento económico" (Niblett, 2020). Otros atalayan las necesidades del futuro al plantear que "ante un futuro coronavirus es que debemos pensar en la atención sanitaria en términos globales en lugar de nacionales [...] ahorrar dinero a corto plazo puede costarnos mucho más cuando una crisis golpea. Los países que han ahorrado dinero recortando los servicios de salud, ahora pagarán mucho más como resultado de la epidemia" (Harari, 2020).

Los analistas políticos y diversos intelectuales han atizado el debate revisando las nuevas estructuras de poder, el rol del Estado: ¿sólo represión y violencia o Estado benefactor? Ya a nivel mundial polemizaban desde marzo el pensador esloveno Slavoj Zizek y el coreano Byung Chul Han. Zizek ha planteado la vuelta a una suerte de comunismo renovado ante la presencia protagónica del Estado, si bien augura 
la caída del Estado chino y nunca más el estatismo soviético. Byung Chul Han lo ha contradicho sosteniendo que ningún virus tumbará al capitalismo sino masas organizadas y que son los países asiáticos son los que mejor vienen saliendo de esta pandemia, no así los europeos. Podría darse el caso de que China venda su Estado policial digital como un modelo exitoso contra la pandemia. Nada de esto augurará la caída del capitalismo que puede volver con más pujanza y, además, con un control digital sobre toda la población, cosa común en los países asiáticos. Así pues, el estado de excepción, es decir, el control digital de las poblaciones se convertiría en la nueva normalidad.

Ha insistido Byung Chul Han que no habrá ninguna revolución viral ya que los virus no hacen la revolución sino las masas organizadas y precisamente la cuarentena generalizada, fomenta el individualismo y los temores encerrando a la población en sus cubiles domésticos aislándola de toda fraternidad y solidaridad. Los virus nos aíslan, no generan ningún sentimiento colectivo fuerte que no pase por el elemental instinto de supervivencia. No hay ninguna solidaridad que se construya separado de los demás. Las distancias mutuas alimentan la noción de separatidad, de otredad y nunca una solidaridad que permita a la humanidad imaginar la utopía de una sociedad más igualitaria y libre. Por tanto, coincidirían Byung Chul Han e Ignacio Ramonet en que está incubando la figura política de Estados controlistas policiacos. La pandemia es una excelente excusa y tiene un sustento sublime para concretarse: nada menos que salvar a la humanidad de la muerte.

Otros han terciado en este debate hablando de la reaparición del capitalismo de Estado con lo que el modelo global habría caducado, ya que es antitético con el Estado. ¿Y que vendrá después? ¿Habrá una nueva globalización? ¿De qué tipo? ¿Un neodesarrollismo con presencia del Estado? ¿Una globalización neoliberal con Estado? Lo importante es que ha reaparecido el Estado cautelando el bien público. Ahora hasta algunos empresarios, caso del peruano (Confederación Nacional de Instituciones Empresarias Privadas, CONFIEP, y adláteres), son los primeros en presionar a sus gobiernos para no pagar los impuestos del caso y seguir lucrando del país, viviendo de la explotación mercantilista de los recursos naturales. Todo ello, a pesar de que el Fondo Monetario Internacional, el Banco Mundial, la Comisión Económica para la América Latina (CEPAL), el Banco Interamericano de Desarrollo (BID) planteen que los ricos paguen más que las clases medias y los pobres, cosa que es de sentido común.

¿O estaremos ad-portas de una revolución, anunciada por Immanuel Wallerstein hace casi treinta años? ¿Qué fue del fin de las ideologías y utopías que pregonaba Francis Fukuyama en "El fin de la historia y el último hombre"? Hoy Fukuyama, 
entrevistado en televisión por Andrés Oppenheimer, tiene que reconocer la labor del Estado y como nunca debió el mercado de imponerse a la mala dejando de lado la labor pública del Estado. Además, lamenta lo que puede ocurrir en Estados Unidos de Norteamérica por el carácter trágico de la pandemia en ese país y por la brutalidad e ignorancia de su presidente, azuzando a sus partidarios a no aceptar los resultados de las elecciones de noviembre, si es que perdiese. Es el supremacismo blanco atemorizado y por tanto más fascista y armado hasta los dientes en unas elecciones que demuestran el colapso de ese país y su declinar como potencia, como ya lo está anunciando a todas luces los sucesos actuales y la bochornosa actuación de Trump.

Fukuyama, luego de haber aplaudido el triunfo de la globalización neoliberal sobre el mundo en 1990, lamenta la trágica visión de un país nada solidario con el dolor pasando de ser un paraíso al país con la mayor tasa de contagios y muertes por el COVID-19.

\section{La geopolítica de nuestro tiempo}

Hemos continuado con el esquema recesivo producto de la quiebra bancaria del 2008 , sin volver a una gran productividad sino a la proliferación del capital bancario o especulativo, el que se ha diferenciado y ha crecido más que el capital real.

El crecimiento nunca rindió a favor del pueblo, que ahora como siempre está en la calle quebrado y hambriento. No solo se viene una posible crisis de hambruna generalizada ante tanta pobreza en el mundo con una economía en recesión sino con posturas fascistoides en Europa, en Estados Unidos, en Brasil con masas atemorizadas, caldo de cultivo para este tipo de estallidos. Acompañan a este cuadro posturas conservadoras que crecen en el mundo entero: el supremacismo blanco, la xenofobia, la homofobia, todos temores a lo diferente en cuanto a género, raza, cultura llevando a intolerancias fundamentalistas, vg. los feminicidios. Pero a la vez, han crecido las movilizaciones de protesta ahora paralizadas por la cuarentena así como los movimientos juveniles, el feminismo más radical que el anterior y Greta Thunberg a la cabeza del movimiento ecologista. La movilización en contra de la policía estadounidense acusada de haber asesinado a George Floyd es un caso emblemático en los Estados Unidos de Norteamérica.

Nunca como hoy el espacio y el tiempo se han vuelto universales para todos y disfrutamos de los mismos adelantos tecnológicos. Cumplidos treinta años de globalización, crecen numerosas crisis y se instala la imagen de una gran crisis sistémica, estructural. Emerge la fuerza de las potencias asiáticas y el protagonismo 
del Océano Pacífico, declinando la fuerza de Europa y del Atlántico norte. De hecho, son los países asiáticos quienes mejor han combatido la pandemia, teniendo los europeos magros resultados al respecto y ni hablar de América Latina, hoy el epicentro de la pandemia, superior al caso africano. El movimiento migratorio es un rasgo de nuestra época, sea el caso de africanos por guerras internas o sequías; el de la población de Medio Oriente bombardeada por la Unión Europea y los Estados Unidos así como miles de centroamericanos pugnando por ingresar al territorio norteamericano y quedándose en México.

Pese a la extensión de los miedos globales y los temores a lo diferente, el mestizaje no ha dejado de crecer. Pero la contradicción central es el enfrentamiento que libran los Estados Unidos de Norteamérica contra la República Popular China, sea a nivel comercial, de las informaciones digitales ( $5 \mathrm{G}$ chino contra el $4 \mathrm{G}$ estadounidense), sea nivel de poderío militar.

Indudablemente que es una guerra que afecta al conjunto de países, iniciada unos años antes de esta pandemia y que no ha amainado con esta epidemia. La naturaleza herida de muerte por la acción ecodepredadora de las empresas transnacionales reacciona con tsunamis colosales, terremotos, lluvias, cambios climáticos e incendios en vastos territorios como el que se generara hace unos meses en Australia, en el África y en nuestra Amazonía, todos ellos producto del recalentamiento global producto de un sistema de industrialización en base al fósil petróleo, gran erosionador del medio ambiente.

Finalmente, hemos ingresado en el ciclo de las epidemias internacionales y de las cuarentenas planetarias, lo cual pese a su signo trágico, no ha llevado a disminuir los enfrentamientos entre las potencias. Queda para la investigación la llamada guerra bacteriológica y su utilización de parte de los países involucrados en la contienda mundial. Lo que sí se observa es que los Estados Unidos ha perdido todo nivel de respuesta y de liderazgo. No sólo no ha encabezado una respuesta planetaria al coronavirus, sino que ha acabado siendo el país más infectado por el mismo. Su actuación ha sido errática, continuación de una política aislacionista que abandona a la Organización Mundial de la Salud en plena pandemia, deja su participación en la Organización de las Naciones Unidas para la Educación, la Ciencia y la Cultura (UNESCO), abandona el acuerdo por el cambio climático y otros acuerdos planetarios en bien de la humanidad.

Ante la globalización, tradicionalmente y por definición aperturista (de mercados, del mundo social, cultural), aparecen en escena gobiernos globales de factura proteccionista, aislacionista en el plano diplomático; si bien fomentan la ingerencia en otros países. Con una conducta política de falta de brújula, se revela 
que la pandemia está interviniendo en la geopolítica, ello porque es una crisis que se comporta como un hecho social total, es decir, no afecta solamente lo sanitario, sino lo social, lo económico, político, ideológico, recreación, mundo de subjetividades, desigualdades y diversas brechas.

Así como Estados Unidos carece de liderazgo ante la pandemia actual, igualmente, las Naciones Unidas han brillado por su ausencia, haciéndonos ver la ineficacia de la vieja normalidad (Ramonet, 2020). China, cuna de este virus, ha logrado combatir con éxito la epidemia y ha mostrado solidaridad con diversos países, al igual que Rusia y Cuba. Hacia el futuro, se consolida una nueva normalidad que instala el trabajo virtual, el teletrabajo desde casa. China, con su 5 G y Big Data, trabajando exclusivamente con datos, controlará toda la información de cada individuo en el mundo, sus áreas de interés. Nada está finalmente dicho sosteniéndose una lucha sin cuartel entre los lineamientos proteccionistas del trumpismo que pueden alinearse con la vuelta de los nacionalismos globalizadores, solo que el trumpismo tiene como base de sostén el supremacismo blanco a diferencia del resto de nacionalismos.

Las movilizaciones populares quedan en espera de avances en el control del coronavirus. No olvidemos que antes de la cuarentena, crecían los movimientos juveniles y de mujeres en las ciudades más prósperas del mundo, expresando una desigualdad social manifiesta. La cuarentena ha opacado estos movimientos, lo que avala la concepción de que como nueva normalidad brillará un sistema controlista. A su vez, el comercio internacional se ha reducido al nivel de hace un siglo. Los precios de las materias primas se han derrumbado. Las economías de los países que vivían centralmente de las exportaciones y del turismo han colapsado. Muchas personas de la clase media retornarán a la pobreza. Se impone una moratoria general del pago de deudas y el fin de los bloqueos comerciales a diversos países.

A la lucha en el campo sanitario, importante en una primera fase, sucederá una brutal recesión económica y finalmente los aspectos sociales de una hambruna generalizada, el desempleo masivo, el crecimiento de la delincuencia. Es de suponer que aumentarán las revueltas callejeras, las luchas por el empleo y el salario.

\section{Mundos futuros posibles}

¿Será lo más conveniente volver al pasado, a la vieja normalidad? ¿O habrá que reconocerse que esa vieja normalidad es la causante de esta crisis? Una posibilidad es que, haciendo oídos sordos a lo aprendido en estos últimos meses, la humanidad 
vuelva al viejo modelo global neoliberal de un modo más radical que antaño con el control digitalizado de cada poblador (Boff, 2020). Un segundo mundo posible sería un capitalismo verde que, sin cambiar la ley de la ganancia y del beneficio, introdujera la variable ecológica en el modelo reforestando lo devastado. Una tercera alternativa sería un colectivismo o comunismo de tercera generación, que dejando de lado el viejo estatismo soviético, colocara todos los bienes y servicios del planeta bajo una administración colectiva y central. En esta alternativa estarían Zizek y Badiou, solo que por los prejuicios frente al estatismo soviético, controlista y represor, tiene pocos seguidores.

Una cuarta alternativa sería el ecosocialismo, que partiría de un gran contrato social con un centro plural de gobierno para resolver los problemas globales de la humanidad. Los bienes se repartirían equitativamente. La quinta alternativa sería el BUEN VIVIR, que es parte de la concepción andina, profundamente ecológica y que considera que todos los seres vivos tienen derechos. La gran disyuntiva y pregunta es: o salvamos a la naturaleza y al planeta o nos lanzamos todos al precipicio. Una nueva civilización futura debe colocar a la tierra, la naturaleza, la vida en toda su diversidad y la solidaridad en primer lugar si queremos sobrevivir. Rara vez se habla de la naturaleza, aunque el virus haya venido de dicha naturaleza. Lo debemos de recordar (Boff, 2020).

El planeta está herido de gravedad y, por tanto, nosotros también. Se han sobrepasado los límites ecosistémicos siendo uno de los debates centrales del futuro el cómo nos relacionaremos con la naturaleza. El "Green New Deal" es una de las grandes opciones para el porvenir o el anticapitalismo ecologista ligado a la justicia socioambiental, la comunalidad, el decrecimiento y el buen vivir. Estas dos propuestas van en contra de continuar con el modelo del "bussiness as usual" o la "vuelta a la normalidad" (Bringel, 2020). Se desmorona la tesis hegeliana del "fin de la historia" de Francis Fukuyama, como si la historia se pudiera cancelar por decreto mientras el planteamiento mariateguista de "lucha final" aflora prístino en la hora actual, un sentimiento protagónico en bien de la vida que autoconstruye su destino lejano de creer que algún día llegará un milenio mesiánico. Nada de "normalidades" sino anteponer el sentido de lo nuevo, de lo que está emergiendo debido a que hablar de "normalidades" es apostar por el pasado y es una defensa reaccionaria frente a la posibilidad de una mejor vida hacia el porvenir. La llamada normalidad huele a decadencia y pasividad frente a la vida y la historia (Manrique, 2020, p. 4). 


\section{El nuevo futuro se construye al andar}

Pese a la pandemia, las potencias, centralmente China Popular y los Estados Unidos de Norteamérica, siguen luchando por el control mundial. Ella no ha aminorado y se da en términos de guerra comercial, guerra digital, guerra por la tenencia de territorios y recursos, algunos dentro de la visión conspirativa hablan de guerra epidemiológica. El futuro ya no será como antes. Además de nuevos repartos del poder, de los avances de la marcha de la franja y ruta de la seda china y del declive de la hegemonía norteamericana (billonaria deuda externa, aumento del comercio chino, errática política internacional y nacional del presidente Donald Trump, aumento de los contagios y letalidad, elecciones gubernamentales en el mes de noviembre), es muy probable que reaparezca la necesidad de la presencia del Estado cautelando el bien público y regulando las relaciones del mercado con la sociedad.

En términos de la vida cotidiana, en plena circunstancia de epidemia planetaria, la agonía de estos meses esperando la vacuna define el accionar internacional. Sin embargo, no paraliza la vida en su conjunto, el trabajo, las relaciones humanas. La vida se virtualiza, se digitaliza en todos sus aspectos. La nueva normalidad incluirá el control digital siendo esta pandemia la primera epidemia contra la que se ha establecido una lucha digital. De hecho, el COVID-19 se ha convertido en la primera gran enfermedad contra la que se lucha digitalmente, lo que comprometerá la privacidad de los habitantes del planeta. El rastreo de los celulares, aunque sea para la buena causa de detectar los niveles de contagio o infección, abre la posibilidad de una vigilancia masiva digital, lo que, pasada la pandemia, tal vez se convierta en una costumbre habitual.

Con o sin vacuna, la distancia física es necesaria para resguardarnos ante la posibilidad de contagio. Para comunicarnos hay celulares, teléfonos domiciliarios, públicos, whatsap, etc. No hablamos de distanciamiento social en un mundo tan polarizado por las desigualdades y brechas sociales sino de distancias físicas. Acentuar el distanciamiento social sería acentuar las desigualdades sociales en la región más disímil del planeta. Debemos usar mascarilla en las calles por varios meses más marcando la distancia física de dos metros, lavándonos las manos y cambiando de ropa en general, de zapatos en el hogar. Pero dicho esto a gente pobre que vive en un solo cuarto, es pedirles demasiado cuando lo principal para ellos es sobrevivir ante la hambruna. El realismo lleva a tratar a los pobres como tema central de la agenda social y cobrar más impuestos a los que más tienen. Los pobres necesitan del apoyo del Estado debiendo éste actuar con el rigor necesario, con el apoyo de la 
Iglesia, los gobiernos locales, el ejército y policía para que los bonos y las canastas de alimentos lleguen a todos los pobres.

No venceremos a la pandemia sin un proyecto nuevo de sociedad a construir, una noción de bien público, de solidaridad y de vida colectiva. El futuro no está escrito aún. Lo construiremos día a día con esperanza, fe y trabajo, pese a los negros presagios del FMI que plantea que la recesión económica será peor que el crack de 1929. CEPAL anuncia que creceremos como región $-5.3 \%$ y el mundo lo hará igual hasta el próximo año. No olvidemos, además, que la pandemia ha llegado a la región latinoamericana luego de varios años de crecimiento reducido, unido a la caída de los precios de las commodities. Es el momento de repensar el rol del Estado y reformular el contrato social, no solo para la pandemia sino para la reactivación económica y el mundo menos globalizado que heredaremos. El Estado debe incentivar el crecimiento, desarrollo productivo y tecnológico, aumentando los sistemas tributarios que pagar. Hay que redistribuir más, tener una cuota de género femenino mayor y preocuparnos más por los más necesitados. Consolidar un Estado de bienestar y una renta básica para todos los ciudadanos sea para momentos ordinarios como extraordinarios.

La educación, salud, vivienda y la vacuna anticovid-19 deben ser gratuitas, para todos y de alta calidad. Hemos ingresado a un tiempo en el que las epidemias serán habituales y parte constitutiva de nuestras vidas.

\section{Bibliografía}

Boff, L. (2020). Transición ecológica hacia una sociedad biocentrada. América Latina en movimiento.

BRINGEL, B. (2020). "Cuidar la vida: crisis ecosocial y horizontes de futuro". En Boletín 23 de la Asociación Latinoamericana de Sociología (ALAS).

CHOMsky, N. (2020). Il Manifesto. Emisión televisiva.

CEPAL, (2020). Comisión Económica para América Latina y el Caribe. Recuperado de www. cepal.org

FORRESTER, V. (2002). Una extraña dictadura. México D.F.: Fondo de Cultura económica.

FuKUYAMA, F. (1992). El fin de la historia y el último hombre. Madrid: Siglo xxi.

GIDDENS, A. (1998). Sociología. Madrid: Alianza Editorial.

HARARI, N (2020). “Pensar en términos globales para luchar contra el coronavirus y el cambio climático". En El País, 22 de marzo de 2020.

LANDER, E (2000). La colonialidad del saber: eurocentrismo y ciencias sociales. Perspectivas latinoamericanas. Buenos Aires: CLACSO. 
MANRIQUE, A. (1995). José Carlos Mariátegui. La emoción de nuestro tiempo. Dos concepciones de la vida (A propósito de la vieja y nueva "normalidad" neoliberal). Recuperado de: https://www.marxists.org/.../dos\%20concepciones\%20de\%20la\%20v... MoRIN, E. (2007). “El Estado-nación en la era planetaria”. En. Babel Gaceta N 1, p. 2.

QuiJano, A (2010). Conferencia dictada sobre "Colonialidad del poder y el Perú" en la Universidad Ricardo Palma.

RAMONET, I. (2020). “Pandemia y el sistema-mundo". En Le Monde Diplomatique. Recuperado de: https://mondiplo.com/la-pandemia-y-el-sistema-mundo

"La pandemia está estableciendo la crisis del modelo neoliberal". Entrevista en Cuartopoder, junio de 2020.

WALLERSTEIN, I. (2009). “El sistema que salga de la crisis será muy diferente”. En Sociológica $N^{a} 1$, pp. 38-52. 